\title{
Morphological Maps of the Fundy Coast*
}

\author{
J.W. WELSTED
}

Department of Geography, Brandon University, Brandon, Manitoba

\section{Introduction}

The grounding of the ARROW on cerberus ROck in Chedabucto Bay on February 4, 1970, and the collision between the two freighters, SUN DIAMOND and ERAWAN, off Point Grey in the Strait of Georgia on September 25, 1973, led to oil spills which contaminated the neighbouring coastal areas. These two events illustrated dramatically the need for detailed knowledge of the coast when planning cleaning up operations (Owens 1971a, 1971b), but mapping the coastal morphology of Canada would take centuries if based on field observation only. However, the existence of air photographs should facilitate the relatively rapid production of a descriptive coastal classification.

The Bay of Fundy is a convenient starting point for three reasons. First, with supertankers sailing into the Bay of Fundy to unload at Iorneville near St. John, the possibility of an oil spill cannot be ignored. Second, there has been little work done on the coastal geomorphology of the Bay and the accounts that do exist (Goldthwait, 1924; Johnson, 1925) are selective and make no attempt to treat the coast as a whole. Third, a great variety of landforms is exhibited over a relatively short distance (Welsted, 1971).

Rock type and structure, exposure to wave attack, and the large tidal range are factors involved in producing the varied landforms.

Rocks exposed along the coast range in age from Precambrian to Recent, although there is a gap between the Triassic and Pleistocene. They vary from extremely resistant igneous rocks, which are exposed along much of the southwest New Brunswick coast and on which the sea has had little impact at its present level, to easily eroded sandstones and shales occurring axound Cobequid Bay and much of Minas Basin. In some places the sedimentary rocks dip gently, as is the case with the Triassic sandstones around Minas Basin, whereas in other areas, for example between Cape Enragé and New Horton Flats, dips are nearly vertical. Some stretches of coast such as those along the whole of North Mountain and Digby Neck are parallel to the structural trend; others at Cape Mingouin, for example, are at right angles to the structure. Sheltered areas like Passamaquoddy Bay contrast with Cape Enragé and Cape Chignecto which are open to the maximum fetch along the southwest-northeast axis of the Bay. At the mouth of the Bay, where the tidal range is small by Fundy standards, salt-marsh accumulation, and tidal mudflats and sandflats are of limited distribution. However at the extremities (Shepody Bay, Cumberland Basin, Minas Basin; and Cobequid Bay) where the tidal range is great, there are many square miles of marsh, both reclaimed and tidal, and of tidal sand and mudflats.

The fact that a coastal classification might be of practical use adds purpose to the work, but at the same time it must be recognized that the use to which the resulting maps are to be put will partly determine the form the classification takes. For example, maps to be used for planning coastal clean-up operations will probably show an emphasis on the shore platform and the beach (see for example Owens 1971a), whereas maps to be used in planning military defence will probably concentrate more on the form and nature of the cliff (Welsted, 1970).

\section{Objectives}

Initially the principal objectives of this study were: (I) to assess the usefulness of air photographs in the interpretation and mapping of coastal and shore morphology; (2) to assess the usefulness, in terms of speed and accuracy, of simple air-photo interpretation apparatus; and (3) to produce a classification of the Fundy coast that could be plotted on a map of scale 1:500,000. As the study progressed, these objectives were continually modified so that the final objective became: "to produce a series of maps showing a coastal classification for the Fundy coast suitable for publication in a journal".

Equipment and Materials

The following basic materials and simple instruments were available for this study: (I) Stereoscopic air-photo coverage of the Fundy coast on a scale of approximately $1: 16,000$. Photographs of Nova Scotia were obtained from the National Air Photo Library, Ottawa, and photographs of New Brunswick from the New Brunswick Department of Lands and Mines, Fredericton; (2) Complete topographic map coverage on scales of $1: 500,000$, $1: 250,000$ and $1: 50,000$; (3) Geological map coverage at various scales published by the Geological Survey of Canada; and (4) For stereoscopic viewing, a standard pocket stereoscope, a T.M. Pocket Measuring Stereoscope, and a Standard N2 Mirror Stereoscope.

\section{Procedure}

Most of the fieldwork took place during the summers of 1965, 1966 and 1967 before air photographs became available to the writer. Consequently the fieldwork was undertaken without the specific goal of obtaining ground truth for airphoto interpretation. Despite this, the writer decided that the ground control would be sufficient to warrant the use of air photographs to interpret morphology, although in a generalized form.

Interpretation of photographs took place during the years 1968, 1969 and 1970. Information interpreted from air photographs was plotted on 1:50,000 base maps. The various instruments available for viewing the photographs enabled the interpreter to see stereoscopically, to enlarge the stereoscopic image, and to determine heights using the parallax method. As might be expected, the amount of information derived was largely dependant 


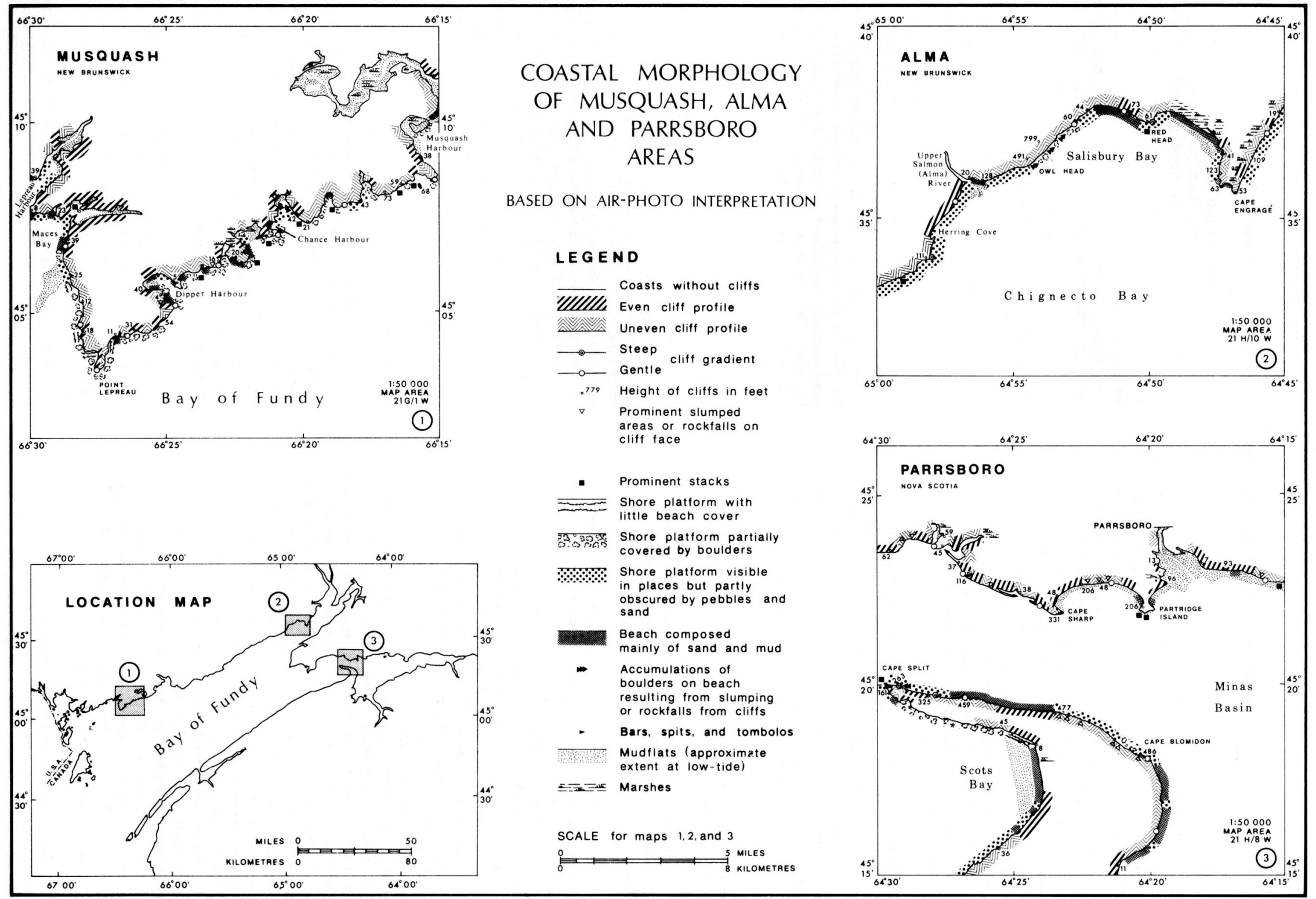

FIG. 1 Coastal Morphology of Musquash, Alma and Parrsboro Areas based on Air-Photo Interpretation. 
on the available ground control; the most detailed mapping possible was for these areas that the writer had visited during the course of the fieldwork. An opportunity to confirm some of the interpretation occurred when the writer visited parts of the North Shore of Minas Basin while attending a meeting of the International Geographical Union's Coastal Commission during August, 1972.

The production of maps of a size and scale suitable for publication was achieved in a series of steps, the first step involving the plotting of information derived by interpretation of the $1: 16,000$ air photographs onto base maps of scale $1: 50,000$. The transfer of data from the $1: 50,000$ base maps onto a 1:500,000 map required so much generalization that it was decided to increase the scale of the final map to $1: 250,000$ and to produce three detailed maps of sample areas at a scale of $1: 50,000$ (Welsted, 1969).

The resulting maps were a manageable size (1:50,000--29 inches $x 18$ inches: $1: 250,000--48$ inches $\times 32$ inches) for office reference, but were too large for publication in a journal. A further reduction of scale was necessary. The three $1: 50,000$ maps were redrafted to a scale of $1: 132,000$ and the $1: 250,000$ map to a scale of $1: 660,000$. Even so, the maps were still too large so they were reduced photographically to scales of $1: 203,500$ (Fig. 1) and $1: 1,017,500$ (Fig. 2) respectively for inclusion in this paper.

\section{The Maps}

\section{a. Detailed Maps of Specific Areas (Fig. 1):}

The areas selected for mapping at the larger scale are on 1:50,000 topographic sheets $21 \mathrm{G} / 1 \mathrm{~W}$ (Musquash), 21H/10W (Alma), and $21 \mathrm{H} / 8 \mathrm{~W}$ (Parrsboro). These areas were chosen because they show a great variety of coastal forms.

Coasts were divided into those having cliffs and those without cliffs. Where cliffs are absent, the land slopes to the sea with no obvious waveformed notch, or else the coast is backed by marsh with no cliff occurring between the open sea and the marsh. Having made this distinction, the next step was to derive data about the nature of the cliffs where they occur. As this study was financed in part by the Defence Research Board, the categorization of cliffs was based on criteria that were thought by the writer to be of some significance for the purpose of national defence. Thus cliffs were categorized as even or uneven, and with steep gradient or gentle gradient. In both instances the division between one type and another was largely subjective. An even cliff is one which has a uniform slope towards the sea throughout its length, whereas an uneven cliff has a ledge (or ledges) between zones of steep slope.

The gradient of the cliff face was determined by measuring the height difference between the top and bottom of. the cliff, and then by measuring the horizontal distance between the top and bottom. The gradient, in degrees, was obtained by dividing the vertical distance by the horizontal distance. on the 1:50,000 base maps, symbols were used to indicate the gradient of the cliffs in 15-degree intervals. However, as there was considerable potential for error in determining the gradient, for example the difficulty of locating the top and the bottom of gentle cliffs in well-wooded areas, and as any gradient determined is valid for one point only, it was decided to eliminate the symbols on the final maps and to use the arbitrary designations of "steep" and "gentle".

As is always the case when grouping landforms, the extreme cases were easily distinguished so that no difficulty arose in deciding that vertical cliffs which eroded into uniform, soft Triassic sandstone should be classified as even cliffs with a steep gradient, nor in deciding that slumped cliffs developed in surficial gravels, sands, and clays should be classified as uneven cliffs with gentle gradient. The intermediate situations were more difficult and it is possible that some inconsistency on the maps arise owing to the subjective nature of the decision making. A completely objective approach would have been easier to apply, but there are valid arguments for using a subjective approach. For example, the nature of the adjacent coast might affect the manner in which an observer perceives a cliff: a stretch of coast might be said to have a steep cliff gradient if bordered on either side by marshland, but the same gradient might appear to be gentle if the area in question is bordered by vertical cliffs. This impression was thought to be of some significance on maps which might be used for defence purposes.

Two other aspects of the cliffs were mapped. They were the cliff height and the location of prominent slumps or rockfalls on the cliff face. The location of prominent stacks was also indicated. The cliff was measured from the shore platform/ cliff contact to the top of the cliff, usually a change in gradient not always easy to locate on the photographs. Obviously there is a limit to the number of heights that can be determined and any height indicated on the map applies to one point only. Prominent slumped areas and rockfalls along steep cliffs provide relatively easy access to the shore from the cliff top and vice versa. Consequently they are plotted on the three maps referred to earlier, the best examples being along the coast northwest of Cape Blomidon.

The maps also show detail of the shore platform and the beach. Along some parts of the coast there is a well-developed shore platform cut into consolidated bedrock with no beach covering. In some areas it is partially covered by boulders, pebbles, and sand, and in other areas there is a complete covering of sand and mud so that the shore platform is not visible. Rockfalls obscure the platform in some places and the more prominent of these are mapped.

Around the Fundy Coast there are numerous examples of bars, spits and tombolos. These are easily located on the air photographs by virtue of their position with respect to the coast as a whole, their linear shape, and their light tone. Several of these features are located in the areas mapped on Figure 1. An elongated isosceles triangle is used to symbolize them, the base of 


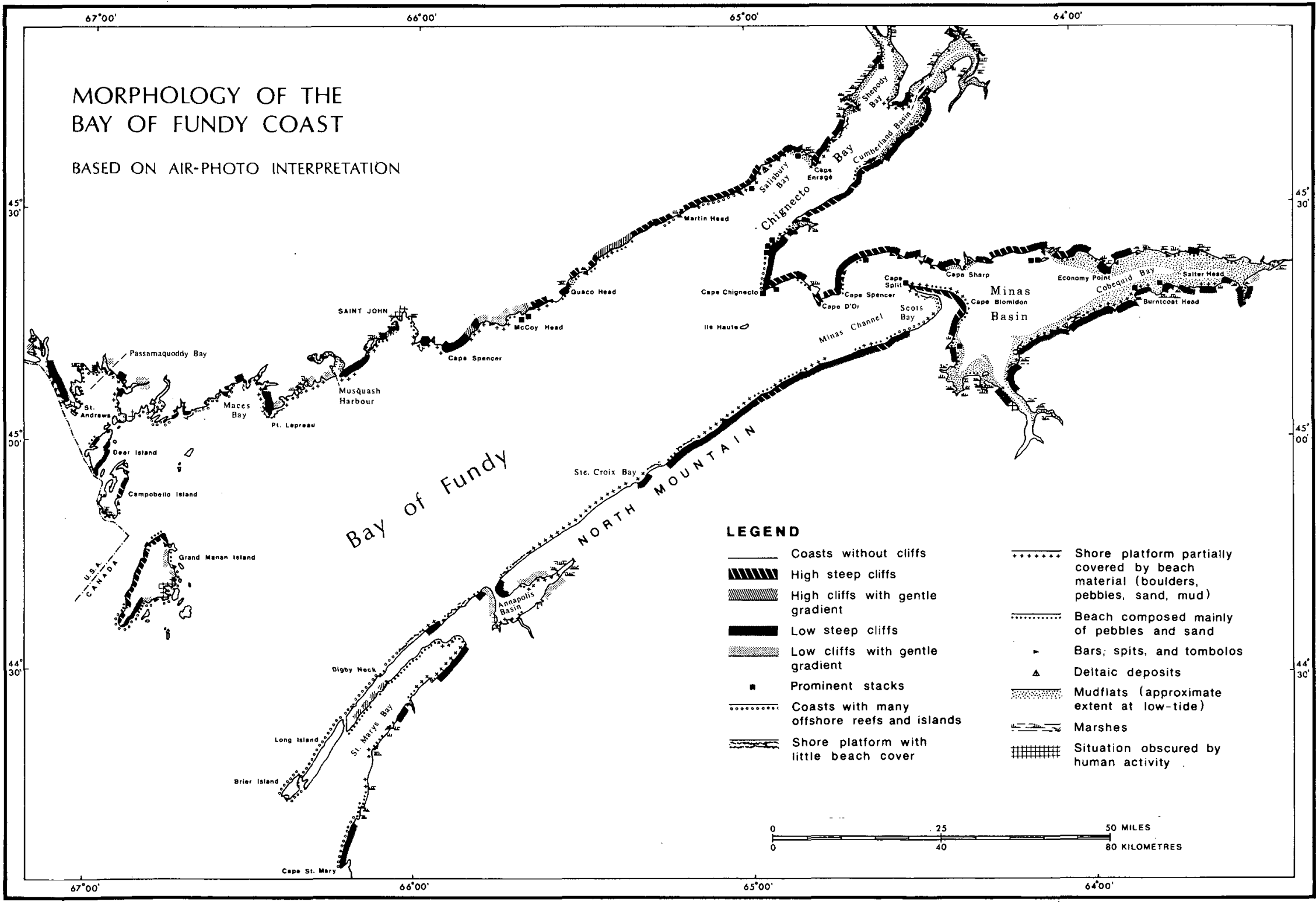


the triangle being at the end of which the depositional landform is attached to the mainland, if indeed it is attached at only one end.

Sand and mud are easily distinguished on the air-photographs; sand having a light grey, almost white, tone and mud being imaged with a silky grey appearance. The dendritic drainage pattern of the tidal mudflats is another distinguishing feature. Plotting the landward extent of the mudflats presented no problem. However, it was much more difficult to plot the seaward extent because the mudflats of the Fundy area are water-covered at high tide and a single photograph can record the coast at any state of the tide. Consequently, the approximate extent of mudflats at low tide shown on Figure 1 was obtained not by air-photo interpretation, but by reference to the relevant topographic maps and hydrographic charts. It is, therefore, only a general indication of the extent of mudflats.

Marshes are widespread along the Fundy coast; some are tidal and are regularly covered by sea water," and others are protected from the sea by dikes and dams. No attempt was made to differentiate on the maps between tidal marshes and protected marshes. Moreover, in some cases the marshes extend several miles back from the present shoreline, but the symbol for marshes was plotted only along the immediate coastal fringe.

Reduction of scale from $1: 50,000$ to $1: 132,000$ did, of course, involve a good deal of generalization. Appropriate symbols had to be devised for the various data being plotted, complex situations had to be simplified, and a large amount of information eliminated. Decisions on what to include and what to omit were based largely on the graphic limits. For example, details of the cliffs, shore platform, and beach are shown in Figure 1 by line symbols which, in width, have a ground distance of approximately 1500 feet. This is much greater than their true extent in most cases. However, had they been shown true to scale, they would not have been Likewise, the shortest possible, clearly visible, length for one of the line symbols represents a ground distance of approximately 1100 feet. Consequently any distinctive stretch of coast which is less than 1100 feet long was either omitted or exaggerated in length so that it could be clearly seen. Some small features were thought to be of sufficient importance to warrant showing although their size had to be exaggerated. This is true of most of the stacks plotted (as filled squares) on Figure $I$ which have ground dimensions of 770 feet $x 770$ feet; greater than the actual size of the stack in most cases. All information plotted on the maps had to be sufficiently large to withstand a reduction from $1: 132,000$ to $1: 203,500$ without becoming indistinguishable. This reduction was required so that the maps could be published in this paper. It was accomplished by photographic methods and no further elimination of detail was necessary at this stage.

\section{b. General Map of the Whole Fundy Coast (Fig. 2):}

This map also required a considerable reduction in scale. Initially information was plotted on 1:50,000 base maps (44 in all). The information was then generalized so that it could be transferred to a $1: 250,000$ base map. The next step was a cartographic reduction in scale from $1: 250,000$ to $1: 660,000$ and the final step was photographic reduction in scale, without further generalization, to $1: 1,017,500$. Clearly, a large amount of detail had to be omitted and the symbols used had to cover a wider variety of situations than on the detailed maps. The basic distinction between coasts with cliffs and those without was maintained, but no attempt was made to differentiate between even and uneven cliff profiles: An arbitrary distinction was made between high cliffs and low cliffs, and steep gradients and gentle gradients although a precise height and gradient were measured at several localities. On Figure 2, there are deliberately no definitions of "high" or "steep" because .it was thought that a statement such as: "cliffs are over 100 feet high and have a gradient greater than $60^{\circ}$ ", gave a false sense of accuracy when the measurements had been made at selected localities only.

On the map, information about the shore platform and the beach was plotted although the situation was more generalized than on Figure 1. Also, the major depositional landforms such as bars, spits and tombolos were again mapped but it was impossible to show them other than by symbols (the elongated isosceles triangle with its base attached to the mainland where the landform is attached). In Figure 1 however, it is possible to distinguish them on the basis of the coastal outline. Mudflats and marshes were shown and the constraints noted for Figure 1 apply again in this case.

In Figure 2, the shortest stretch of coast that could be clearly shown by the line symbols for cliffs, the shore platform, and the beach were in the order of 5,500 feet. All the rockfalls indicated in Figure 1 are smallex than this and consequently they have been omitted from Figure 2 . Stacks, however, are shown in Figure 2, but there are fewer indicated than in Figure 1 . Where there were too many stacks to show individually, the coast was mapped as one with "many offshore reefs and islands". The smaller scale of Figure 2, did, however, enable deltaic deposits to be shown by means of a single point symbol, whereas in Figure 1 several point symbols would have been needed to cover the deltaic areas at the mouths of the Upper Salmon River and the Parrsboro River. Instead these deltaic areas are shown in Figure 1 as areas of mudflats although they are not composed entirely of mud.

At a few locations around the Fundy coast it is difficult to distinguish the "natural" form of the coast because of human interference. No situations like this occur in the areas covered by Figure 1, but taking the whole coast into consideration there are several. These areas have been assigned a separate symbol in Figure 2 .

\section{Conclusions}

The maps represent, as far as is known to the writer, a first attempt at mapping the morphology of the Fundy coast. Although the maps show data 
which have been distinguished somewhat arbitrarily, it is thought that they represent a significant contribution to the knowledge of the area. The amount of detail shown on the maps can easily be obtained by use of air photographs which are readily available. Future efforts should concentrate on establishing more accurate ground control and establishing objective boundaries between the various morphological parameters. The main difficulty in producing the maps lies not so much in the air-photo interpretation, as in devising a valid cartographic system for plotting the observed data. It should be noted that the scale of Figure $2(1: 1,017,500)$ is close to the scale of ERTS imagery of the area. With this in mind it would be worth interpreting the relevant ERTS imagery to determine whether a map at the same scale, and with as much detail as Figure 2 could be derived from it. If it is feasible, it will involve virtually no change in scale and will eliminate the series of steps involved in the present interpretation.

\section{Acknowledgements}

Research for this paper was financed by National Research Council grant $A 4265$ and by Defence Research Board grant 9511-80. Air photo interpretation was carried out by the following former undergraduate students of Brandon University: T. Carter, K. Dando, R. Metcalfe, G. Saunders, V. Sharratt, and G. Shearer.
References

GOLDTHWAIT, J.W., 1924, Physiography of Nova Scotia. Geol. Surv. of Can., Memoir 140, pp. 179.

JOHiNSON, D.W., 1925, The New England - Acadian shoreline. New York, John Wiley and Sons Inc., pp. 608 .

OWENS, E.H., 197la, A reconnaissance of the coastline of Chedabucto Bay. Marine Sciences Branch, Marine Science Paper 4, pp. 24.

, 1971b, The restoration of beaches contaminated by oil in Chedabucto Bay, Nova Scotia. Marine Sciences Branch, Marine Science Report 19, pp. 75.

WELSTED, J.W., 1969, Physiographic classification of the Bay of Fundy coast based on air-photo interpretation--A Progress Report. Maritime Sediments, Vol. 5, No. 3, pp. 135-137.

1970; A physiographic and erosional classification of the Bay of Fundy coast. Unpublished Report to the Defence Research Board, pp. 6 .

1971, Morphology and evolution of the Bay of Fundy with emphasis on changes of sealevel during the Quaternary. Unpublished Ph.D. Thesis, Bristol University, pp. 253. 